\title{
A Hidrologia de Chapecó/SC: alterações nas bacias hidrográficas urbanas a partir do processo de urbanização do município
}

\author{
The Chapecó's hydrology: changes in the urban hydrographic basins \\ starting from the urbanization process in the municipality
}

\section{Cássia Regina Segnor',Juçara Spinelli "}

O presente artigo apresenta a situação dos rios urbanos de Chapecó/SC, em associação a eventos de inundação e alagamento na cidade, ao longo do seu processo de urbanização recente e consolidação enquanto cidade média no oeste catarinense. Este estudo busca revisitar a transição do Brasil rural até a década de 1940 para um país com características urbano-industriais e debater a relação deste processo com as questões urbano-ambientais. Evidencia fortes transformações decorrentes do uso e ocupação do solo urbano e problemas de infraestrutura de drenagem urbana em Chapecó/SC, destacando que são recorrentes em inúmeras cidades brasileiras as quais carecem de uma adequada atenção com planejamento via plano diretor de drenagem urbana e iniciativas de governança.

Palavras-chave: Bacias hidrográficas; drenagem urbana; urbanização

\section{ABSTRACT}

This article presents the situation of the urban rivers of Chapecó/SC in association with events of flooding and overflow in the city after the recent urbanization process and consolidation as a middle size city in western of Santa Catarina. This study seeks to review the transition from Brazil's rural phase until the 1940s to a country with urban-industrial characteristics and to debate a relationship between this process and urbanenvironmental issues. It evidences strong changes resulting from the use and occupation of urban land and problems of urban drainage infrastructure in Chapecó/SC, highlighting that they are recurrent in several Brazilian cities that need adequate attention with planning through the urban drainage master plan and governance initiatives.

Keywords: Hydrographic basins; Urban drainage; Urbanization

\section{INTRODUÇÃO}

Chapecó é um município do oeste de Santa Catarina, sede tanto da Região Geográfica Intermediária quanto da Região Geográfica Imediata que levam seu nome

\footnotetext{
Arquiteta e Urbanista (UNOCHAPECÓ), mestranda em Geografia pela Universidade Federal da Fronteira Sul.. E-mail. cassiasegnor@gmail.com ORCID: $\quad$ https://orcid.org/0000-0003-2483-6235

" Mestre em Planejamento Urbano e Regional e Doutora em Geografia pela Universidade Federal do Rio Grande do Sul E-mail. jucara.spinelli@uffs.edu.br ORCID https://orcid.org/0000-0003-1233-1387
} 
(IBGE, 2008). Com uma população de 183.530 habitantes (IBGE, 2010), sua área total é de $624,8 \mathrm{~km}^{2}$ (IBGE, 2019a), dos quais 113,2 km² correspondem ao perímetro urbano (CHAPECÓ, 2011). Sob o aspecto geomorfológico, o município localiza-se no Planalto Catarinense, mais especificamente no Planalto Oeste da Bacia Hidrográfica do Rio Uruguai, drenado por rios com lineamentos predominantemente E-W, SW-NE e N-S (PELUSO JÚNIOR, 1986).

Assim como na grande maioria das cidades brasileiras, o município de Chapecó/SC iniciou seu incremento populacional a partir da segunda metade da década de 1960. A confirmação de sua inversão demográfica rural para urbana, contudo, deu-se apenas na década de 1980, quando a população residente nas cidades correspondia a $66 \%$ em comparação a $34 \%$ residente no campo (NASCIMENTO, 2015).

Essa dinâmica demográfica, resultado do processo de urbanização, acabou por transformar o espaço urbano de Chapecó/SC drasticamente, inclusive sob o aspecto hidrológico. O objetivo desse artigo é, portanto, verificar as alterações nas bacias hidrográficas urbanas de Chapecó/SC a partir de sua formação e expansão territorial, com enfoque particular à problemática de drenagem urbana que se intensificou sobretudo nas últimas décadas.

Tendo por base essa discussão, a pesquisa se constituiu com a utilização de uma metodologia descritiva e analítica, partindo de uma revisão bibliográfica acerca da urbanização brasileira, da rede urbana recente, com destaque às cidades médias e os impactos da intensificação da ocupação na drenagem urbana. Um breve apanhado da situação do tema da drenagem urbana no Brasil e as medidas corretivas necessárias ao uso do solo urbano também foi apresentado. Adentrando especificamente na urbanização de Chapecó/SC e no estudo das bacias hidrográficas em área urbana, os dados e informações foram compilados pela base do IBGE, do SIRHESC (Sistema de Informação de Recursos Hídricos do Estado de Santa Catarina) e de outros órgãos públicos regionais e municipais, além do aprofundamento de um estudo já realizado por BINDA et al (2012) que apresentou o mapeamento dos casos de inundações e alagamentos nas décadas de 1980-1990; 1991-2000; 2001-2010. 
Partindo desse estudo, o aprofundamento ocorreu pela análise de medidas e/ou soluções adotadas pelo poder público e a reflexão acerca do papel dos comitês de bacias no planejamento integrado do uso das áreas urbanas.

Este artigo está estruturado em três partes, além da introdução e das considerações finais. A primeira e a segunda descrevem o processo de urbanização que se deu no Brasil, a conceituação de cidades médias e, consequentemente, os problemas de cunho hidrológico, tão recorrentes em grandes cidades e que passam a ocorrer, também, nas cidades médias. Tais episódios e sua análise suscitam uma avaliação e abertura à discussão sobre medidas corretivas de drenagem urbana e ações de planejamento. A terceira parte focaliza a cidade Chapecó/SC e descreve como o sistema de drenagem urbana é organizado no município, sob a perspectiva da recorrência e ampliação dos pontos de inundações e alagamentos na malha urbana. Ainda, faz menções às possíveis soluções para essa problemática urbana por meio de ações de órgãos públicos locais e regionais, a exemplo dos Comitês de Gerenciamento de Bacias Hidrográficas de Santa Catarina.

\section{CONFIGURAÇÕES HIDROLÓGICAS NAS CIDADES MÉDIAS BRASILEIRAS}

As mudanças políticas ocorridas na década de 1930, com a regulamentação do trabalho urbano (não extensiva ao campo), incentivo à industrialização, construção da infraestrutura industrial, entre outras medidas, reforçaram o movimento migratório campo-cidade (MARICATO, 2003). A partir desse momento, a industrialização se firma como um fator importante à urbanização brasileira. Segundo Santos (1993, p.9), nesse período, a urbanização brasileira se generaliza e o "[...] turbilhão demográfico e a terceirização da economia são fatos notáveis".

Santos (1993) ainda afirma que o forte movimento de urbanização, a partir do fim da Segunda Guerra Mundial é contemporâneo de um forte crescimento demográfico nas cidades brasileiras, resultado não apenas da taxa de natalidade elevada, mas também de uma mortalidade decrescente em função dos progressos sanitários, a melhoria das condições de vida da população e do próprio processo de 
urbanização. Esse fenômeno, contudo, não se dá de forma homogênea, uma vez que são diferentes os graus de desenvolvimento e de ocupação das regiões brasileiras.

Nesse contexto, a estrutura produtiva é modificada: o Brasil predominantemente rural com suas atividades extrativas e agrário exportadoras da década de 1940 passou a dar lugar à produção urbano-industrial na década de 1950 a partir da "[...] introdução do meio técnico-científico-informacional na cidade" (SANTOS, 1993, p. 36). Ferreira (2010) complementa dizendo que:

\begin{abstract}
Apesar da iniciativa estatal para a criação de diversas instituições e mecanismos para a dinamização do território, em 1950, a população brasileira era predominante rural (...) A distribuição desse contingente populacional urbano se encontrava dispersa pelo território e mais concentrada em algumas regiões como Sul e Sudeste. Com a expansão da malha viária e instalação do setor automotivo em São Paulo, por (JK) Juscelino Kubitschek, nessa mesma década, a rede de cidades começa a ganhar nova configuração e complexidade (FERREIRA, 2010, p.75).
\end{abstract}

Na década de 1960, o avanço da urbanização contribuiu para a criação das metrópoles nacionais em função do aumento do setor de serviços, que na década seguinte acabaram sendo institucionalizadas. Ao mesmo tempo em que elas cresciam, as regiões metropolitanas se estagnavam, diminuindo suas participações na população do país (STAMM, et al, 2013). Nesse período, o golpe de Estado de 1964 acaba se tornando um marco, como menciona Santos (1993) uma vez que o movimento militar criou as condições para uma integração do País com o mercado mundial, através da descentralização das atividades produtivas.

Até o início da década de 1970, a gestão urbana efetuada pelos governos militares esteve centrada numa política habitacional que, retoricamente voltada para a solução das moradias precárias da população mais pobre, passou aos poucos a voltarse para as camadas médias, em busca de maior rentabilidade para o sistema (LOHN, 2011). Contudo, a lógica modernista - e utópica - destas intervenções, acabou por ampliar as diferenças econômicas e sociais nas cidades, escancarando ainda mais a desigualdade das condições de vida entre ricos e pobres.

Em consequência das políticas de modernização da agricultura e diversificação agropecuária, ao movimento de desconcentração econômica e os investimentos em infraestrutura que integraram o interior do país a dinâmica da economia mundial, 
entre 1960 e 1970, intensifica-se o surgimento de cidades com mais de 100 mil habitantes fora do eixo Rio-São Paulo (FERREIRA, 2010). O aumento do número dessas cidades de porte médio ${ }^{1}$ no Brasil, sobretudo a partir da década de 1980, serviu basicamente para conter os fluxos migratórios dos grandes centros. Dessa forma, a difusão espacial das cidades de porte médio foi uma consequência do perfil do desenvolvimento econômico brasileiro e sua urbanização, em detrimento a uma menor participação das regiões metropolitanas na população do país (STAMM, et al 2013).

Aqui se observa o que Santos (1993) chama de "desmetropolização": uma maior distribuição da população no território brasileiro - principalmente nas cidades médias - que acontecia paralelamente ao crescimento populacional cumulativo nas maiores cidades do país, entre 1980 e início da década de 1990. Para Stamm et al (2013, p.264), "[...] enquanto as metrópoles nacionais e regionais apresentam um continuum urbano-industrial, parte das cidades de porte médio localizadas nas áreas de ocupação recente será marcada por um continuum urbano-rural". Essas características reiteram "[...] o quanto a dinâmica populacional brasileira é dependente da dinâmica dos espaços rurais, a forma como ocupa a força de trabalho, e do perfil da demanda bens e serviços das áreas urbanas" (STAMM et al, 2013, p.264).

Porém, no final do século $X X$, a imagem sustentada de progresso e desenvolvimento das décadas anteriores, acabou sendo substituída pelos altos índices de exclusão social e segregação espacial, que agora tornavam-se a expressão da urbanização brasileira. O desenvolvimento desigual das cidades personificou a cidade dual $^{2}$, o que acabou por dividir a urbe entre sua porção legal e ilegal. Sem condições, a população de baixa renda ocupou as áreas periféricas, desprovidas de infraestruturas ou àquelas ambientalmente frágeis, desinteressantes para a especulação imobiliária, enquanto os mais abastados ficaram com as áreas centrais, bem equipadas e valorizadas. Santos (1993) complementa dizendo que: 
vivem cada vez mais nos espaços urbanos. A indústria se desenvolve com a criação de pequeno número de empregados, e o terciário associa formas modernas a formas primitivas que remuneram mal e não garantem a ocupação (SANTOS, 1993, p.10).

O processo de urbanização pelo qual passou a sociedade brasileira foi certamente uma das principais questões sociais do país no século passado (ROLNIK, 2000). Desde então, esse processo se firma como o principal desafio das cidades a partir do século XXI, no que concerne o equilíbrio entre o impacto ambiental proporcionado pelas ocupações massivas e o impulso econômico ao desenvolvimento urbano. Assim, resultado da falta de planejamento, apenas com discurso progressista, as cidades tornaram-se cada vez mais espaços polarizados, passando a não só retratar como reproduzir as injustiças e desigualdades sociais de um modo cada vez mais expressivo.

É notório que analisar o urbano contemporâneo tem se evidenciado como uma tarefa complexa devido os constantes processos de estruturação e reestruturação aliado a multiplicidade das relações que ocorrem nas cidades (ZANDONADI, 2013). Além disso, muitas dessas análises acabam classificando as cidades apenas de acordo com seu caráter demográfico, o que de certo modo, torna-se incompatível com os papeis que estas desempenham na rede urbana em que estão inseridas.

O termo "cidade média", apesar de recorrente, ainda não tem uma definição precisa, fato relacionado, como menciona Zandonadi (2013), a sua intricada classificação hierárquica no contexto das relações estabelecidas por elas. Ainda na década de 1970, Andrade e Lodder (1979) consideravam como cidades médias, centros urbanos com população entre 50 mil e 250 mil habitantes. Em estudo mais recente, de acordo com o censo de 1991, Maricato (2001) e IBGE (2000) acabaram por considerar dentro desse conceito àquelas que apresentassem uma população urbana entre 100 mil e 500 mil habitantes.

Já Santos (1993), ao contrário dos demais, havia definido como parâmetro para uma cidade média, não apenas a quantidade mínima de 100 mil habitantes, mas também o seu papel na rede urbana, regional e nacional, uma vez que a expansão e a 
diversificação do consumo fariam com que as cidades concentrassem cada vez mais um acúmulo demográfico e de atividades.

Nesse sentido, Sposito (2010, p.52) propõe a diferenciação de nomenclaturas no que ela considera cidade de "porte médio" e "cidade média". Para a autora, as cidades médias são aquelas que desempenham papeis de intermediação nos sistemas urbanos, enquanto as de porte médio são definidas, exclusivamente, em função de seu tamanho demográfico.

Categorizar uma cidade média baseada apenas no seu aspecto populacional torna-se cada vez mais obsoleto diante das novas dinâmicas urbanas. Souza (2003) ilustra essa condição comparando a realidade de uma cidade média no Nordeste brasileiro e outro no Sul: enquanto a primeira não dispõe comércios e serviços diversificados/sofisticados, uma vez que está situada em uma região pobre, a segunda é detentora de condições econômicas melhores, visto que está em uma local mais favorável.

A partir dessa perspectiva, Sposito (2010) considera que as novas relações nas redes urbanas, em função do processo de globalização, acabam por romper o sistema hierarquizado de dependência das cidades pequenas com as cidades médias, e destas com a metrópole. As cidades dentro de seus contextos mais diferenciados passam a relacionar-se entre si sem o intermédio de outra em posição superior. Essas articulações diversificadas, no âmbito de uma mesma rede ou não, poderiam ser resultado "[...] tanto das relações competitivas, tão caras ao novo sistema produtivo, como relações de sinergia que geram complementaridade de ações realizadas em diferentes pontos do mundo" (SPOSITO, 2010, p.53). Catelan (2013, p. 38) reforça esse pensamento ao enunciar que:

[...] as cidades médias são caracterizadas na rede urbana, no momento atual, pelo par hierarquia-heterarquia ${ }^{3}$, tendo em vista que as interações espaciais interescalares ampliam sua onipresença regional, quanto maior sua interação com outras escalas (CATELAN, 2013, p. 38).

Tanto para Sposito (2010) como para Catelan (2013), esse novo processo não deve ser tratado como oposição ou substituição as redes hierárquicas, mas sim como uma combinação complementar complexa e contraditória de fluxos, " [...] uma vez que 
uma mesma cidade é o espaço de ação e decisão de atores econômicos que se relacionam em diferentes escalas (SPOSITO, 2010, p.53).

Assim, "[...] as cidades [sobretudo as médias] constituem-se, cada vez mais, uma ponte entre o global e o local, em vista das crescentes necessidades de intermediação e da demanda também crescente de relações" (SANTOS E SILVEIRA, 2001, p. 281) e "[...] nessas cidades, não apenas o contingente demográfico, mas a complexificação funcional é que as diferenciam na rede urbana" (FERREIRA, 2010, p.87).

Contudo, o intenso, e de certa forma rápido, crescimento das cidades médias brasileiras refletiu em significativas mudanças de cunho socioespacial no território urbano. O espaço multifacetado e desigual, característico dos grandes centros, agora também fazia parte da realidade destas cidades. Sobre isso, Cancelier et al. (2015) destacam que:

De forma geral, os espaços urbanos no âmbito das cidades médias tiveram expressivos processos de mudanças estruturais entre os quais o acelerado processo de ampliação das bases populacionais, deficiência de infraestrutura, espraiamento das cidades, encarecimentos dos custos fixos, especulação imobiliária, entre outros. Neste contexto insere-se a cidade de Chapecó (CANCELIER et al, 2015, p.718).

Estes centros urbanos concentraram então problemas ambientais, reflexos do seu (des)ordenamento territorial: adensamento populacional em sítios inadequados, falta de resguardo de áreas de importância ecossistêmica e uso comunitário, gestão e planejamento de paisagens naturais e construídas (VALENTINI, 2015). A produção do espaço urbano ao longo da formação das cidades, que explicitou a negligência com a ocupação coerente do solo, implicou de forma incisiva nos recursos hídricos que fomentaram todo o processo civilizatório. Os cursos d'água cada vez mais descaracterizados passaram, então, a refletir as ações de descaso com a água, fato que aparentemente se tornou normalizado pelas pessoas.

Sobre essas condições, Tucci (2003) menciona que à medida que a cidade se urbaniza, ocorrem grandes alterações no ciclo hidrológico, que acabam por impactar significativamente não só a natureza, mas o próprio homem. O ciclo hidrológico é entendido como um processo natural de evaporação, condensação, precipitação, detenção e escoamento superficial, infiltração, percolação da água no solo e nos 
aquíferos, escoamentos fluviais e interações entre esses componentes (RIGHETTO, 1998).

Em ambientes urbanos, contudo, esse ciclo e suas diversas etapas naturais são reduzidos a apenas escoamento e infiltração. Essa redução é resultado da intensa impermeabilização do solo nas cidades, justificados pelas intervenções humanas de uso e ocupação. Esses fatores, que reduzem de modo radical as infiltrações, favorecem o escoamento das águas mais rapidamente e em grandes volumes, dando origem as enchentes (BOTELHO, 2011). Essas alterações na fisionomia dos rios ao longo da história, especialmente no Brasil, têm acontecido rapidamente nas últimas décadas (CUNHA, 2003), dessa forma "[...] as bacias hidrográficas urbanas, são marcadas pela diminuição do tempo de concentração de suas águas e pelo aumento dos picos de cheia, quando comparadas às condições anteriores à urbanização" (BOTELHO, 2011, p.73).

É preciso mencionar que naturalmente um corpo d'água passa por períodos de cheia e transbordamento. Contudo, nas áreas densamente urbanizadas, geralmente com ocupação intensa e desordenada, além das soluções falhas de drenagem urbana, esse sistema hidrológico é diferenciado (BOTELHO, 2011). Assim, eventos como as inundações e alagamentos se constituem cada vez com mais frequência nas cidades, ampliados pela ação humana que impermeabiliza os solos e canaliza os rios.

Além desses fatores, a ineficiência na cobertura e manutenção dos serviços de coleta de lixo e limpeza urbana (BOTELHO, 2011) e carência de saneamento básico na maioria das cidades brasileiras (CANHOLI, 2014) também se constituem como condições para a situação calamitosa dos recursos hídricos. Em consequência a isso, as medidas corretivas (canalizações, retificações, afundamento de leito, entre outras) efetuadas junto aos cursos d'água, têm-se mostrado ineficazes na resolução da problemática urbana, em grande parte devido ao seu caráter pontual que apenas transfere os impactos de um lugar a outro, o que faz como que os problemas persistam ou, muitas vezes, piorem.

Para Canholi (2014), essas adversidades reiteram a desconsideração da drenagem urbana como um fator importante na expansão das cidades, visto que o 
crescimento delas "[...] não foi acompanhado de instrumentos reguladores do uso e ocupação do solo" (CRUZ e TUCCI, 2008, p.59). Este contexto expõem a falta de uma visão integrada na gestão urbana, em geral de responsabilidade apenas das Prefeituras Municipais, através das secretarias de obras, cujo foco está para problemas localizados ao invés da cidade como um todo, o que impossibilita um planejamento preventivo e ações planejadas que englobem outros setores (água, esgoto e resíduos sólidos) (TUCCI, 2003).

Obviamente, o estado em que se encontra os cursos d'água, irá refletir os cenários naturais e urbanos que automaticamente influenciam na bacia hidrográfica em que estão inseridos (VIEIRA e CUNHA, 2001). Apesar deste cenário, é explícito que a questão da drenagem urbana ainda não é prioridade para os municípios brasileiros (Tabela 1).

Tabela 1 - Municípios brasileiros com Plano Diretor de Drenagem Urbana (PDDrU)

\begin{tabular}{ccc}
\hline Regiões e Brasil & Total de municípios & Plano Diretor de Drenagem Urbana \\
\hline Sul & 1.159 & 122 \\
Sudeste & 1.666 & 72 \\
Nordeste & 1.787 & 41 \\
Centro-Oeste & 446 & 12 \\
Norte & 449 & 9 \\
BRASIL & $\mathbf{5 . 5 0 7}$ & $\mathbf{2 5 6}$ \\
\hline
\end{tabular}

Fonte: IBGE - Pesquisa Nacional de Saneamento Básico, 2000. Atualizado em 20/04/2005. Organização: as autoras (2020).

Menos de 5\% das cidades no Brasil possuem Plano Diretor de Drenagem Urbana, importante mecanismo de gestão da infraestrutura urbana alinhada ao escoamento de águas pluviais e dos rios. Essa situação se agrava nas regiões Norte e Centro-Oeste, que apresentam os menores índices de municípios com PDDrU. Esse desinteresse ou ainda incapacidade de utilização de instrumentos, tais como o PDDrU, colabora para reincidência de eventos danosos de inundações e alagamentos nas áreas urbanas, o que reitera a urgência em se avançar na implantação de medidas de prevenção a curto e longo prazo. 


\section{AS MEDIDAS CORRETIVAS DE DRENAGEM URBANA NO BRASIL}

No Brasil, embora o planejamento de drenagem ainda se constitua como algo recente e incipiente, algumas iniciativas como as BMPs (Best Management Practices) e a LID (Low Impact Development), foram incentivadas para amenizar a problemática no contexto de drenagem urbana. A primeira corresponde a técnicas de controle de escoamento da bacia a partir da sua fonte e não no curso d'água como é frequentemente efetuado, o que evita a transferência de problemas a jusante (CRUZ et al 2007). Já a LID pode ser entendida como uma solução sustentável que busca " [...] o gerenciamento integrado da infraestrutura urbana, iniciando-se pela definição da ocupação do espaço, com preservação das funções naturais, como a infiltração e a rede natural de escoamento" (TUCCl, 2005, p. 141).

Uma experiência de BMPs se deu no final da década de 1990, quando o Departamento de Esgotos Pluviais (DEP) de Porto Alegre/RS, iniciou a elaboração do Plano Diretor de Drenagem Urbana (PDDrU) para o município. O intuito do plano é obter diretrizes técnicas e ambientais junto a gestão da infraestrutura urbana que consistem na não transferência dos efeitos da urbanização para outros pontos da bacia hidrográfica, através do controle de escoamento das águas pluviais, dos rios e arroios (IPH, 2002).

Outras cidades, conforme citam Cruz et al (2007), também adotaram medidas de controle na fonte através de instrumentos legais, como Belo Horizonte, São Paulo, Guarulhos e Caxias do Sul, todavia, ainda há uma grande resistência por parte dos profissionais à aplicação de BMPs nas cidades brasileiras. Quanto à LID, o estímulo a sua utilização partiu do Ministério das Cidades $^{4}$ a partir da implantação do Programa Drenagem Urbana Sustentável (2007) que:

objetiva promover, em articulação com as políticas de desenvolvimento urbano, de uso e ocupação do solo e de gestão das respectivas bacias hidrográficas, a gestão sustentável da drenagem urbana com ações estruturais e não-estruturais dirigidas à recuperação de áreas úmidas, à prevenção, ao controle e à minimização dos impactos provocados por enchentes urbanas e ribeirinhas (BRASIL, 2007, p.04). 
Essas ações estruturais e não estruturais (Figura 1) que estão inclusas nessas iniciativas, são medidas de controle que auxiliam na resolução dos casos de enchente e inundação nas cidades. As medidas estruturais, aquelas que provocam alterações no sistema fluvial a partir de obras de engenharia, podem ter caráter extensivo que incluem ações na bacia hidrográfica alterando as relações entre precipitação e vazão ou intensivo cujas transformações se dão no próprio curso d'água. Já as medidas não estruturais, compreendem um conjunto de medidas preventivas e que prezam por uma melhor convivência da população com estes problemas (TUCCl, 2003).

Figura 1 - Medidas de controle de enchentes e inundações

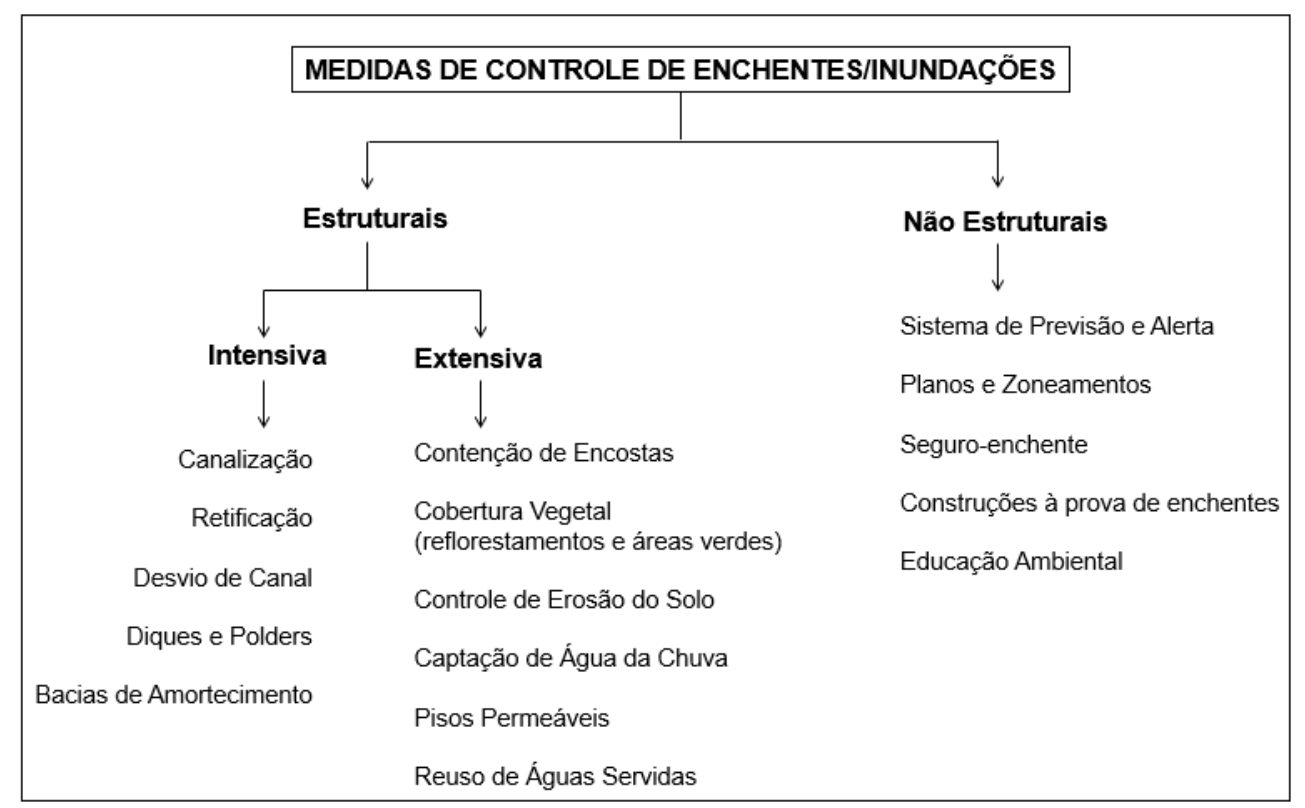

Fonte: TUCCI (2003); BOTELHO (2011). Elaboração: SEGNOR (2019).

As medidas de correção e prevenção que visam minimizar os danos das inundações são classificadas, de acordo com sua natureza, em medidas estruturais (intensivas e extensivas) e medidas não estruturais e englobam diversas ações que vão desde intervenções antrópicas à conscientização da população.

Quanto a essas condições de prevenção e controle de inundações, na concepção de Botelho (2001), as medidas estruturais extensivas e as medidas não estruturais são as mais indicadas por seu custo menor aliado a maior eficiência, visto que as estruturais intensivas não tratam as causas do problema, apenas minimizam seus efeitos temporariamente através de medidas compensatórias. 
Entretanto, como aponta Tucci (2003), nos países em desenvolvimento como é o caso do Brasil e naqueles mais pobres, as ações ainda priorizadas para resolver essa problemática se concentra justamente nessas técnicas estruturais economicamente inviáveis, enquanto nos países desenvolvidos os problemas já estão sendo prevenidos mediante procedimentos não estruturais, mais econômicos e sustentáveis.

Essa realidade, que faz parte da maioria das cidades brasileiras, é refletida também em Chapecó, cuja ruptura com seus corpos hídricos, através principalmente de canalizações e retificações, desvela um distanciamento que foi construído ao longo de toda sua história e que impacta diretamente nas suas bacias hidrográficas urbanas.

\section{O CENÁRIO URBANO CHAPECOENSE}

O oeste catarinense constitui-se como uma importante região agrícola do estado, da qual Chapecó é considerada polo regional e cidade média em função de sua dinâmica e articulações locais, nacionais e internacionais (ALBA et al, 2015). Seguindo a lógica do crescimento nacional, Chapecó começa a ter sua paisagem urbana alterada de maneira mais expressiva na década de 70 em comparação as décadas anteriores, devido ao movimento migratório que caracterizou a cidade na época. Sobre isso, Zeni (2007) escreve que esses impactos ambientais refletiram diretamente nas bacias hidrográficas como consequência da impermeabilização do solo vinculada a fatores como:

retirada da vegetação, falta de áreas públicas de lazer, áreas verdes com esse fim, traçado de ruas em forma de tabuleiros, ou seja, xadrez, causando assoreamento de sedimentos, canalização dos córregos centrais, soterramento das nascentes e cursos de água através dos movimentos do solo (ZENI, 2007, p.41).

Atualmente, com população estimada em mais de 220 mil habitantes ${ }^{5}$, a taxa de urbanização do município já extrapola os $90 \%{ }^{6}$, o que enfatiza as alterações na fisionomia hídrica ao longo dos anos. A canalização e o esquecimento dos rios urbanos sob as lajes de concreto (BINDA, 2015), suprimindo os cursos d'água do contexto urbano, representam em grande parte a visão fragmentada do processo de 
crescimento e desenvolvimento urbano que desconsiderou as bacias hidrográficas urbanas por completo.

\subsection{As bacias hidrográficas urbanas de Chapecó (BHUsC): primeiros olhares}

As BHUsC estão incluídas na denominada Região Hídrica 2 - Meio Oeste (RH2) conforme Figura 2, que engloba a bacia hidrográfica do Rio Chapecó e do Rio Irani. Essas duas bacias são subordinadas à bacia do rio Uruguai que incorpora além deste estado, o Rio Grande do Sul e os países vizinhos Argentina e Uruguai (SANTA CATARINA, 2009).

\section{Figura 2 - Regiões hidrográficas de Santa Catarina}

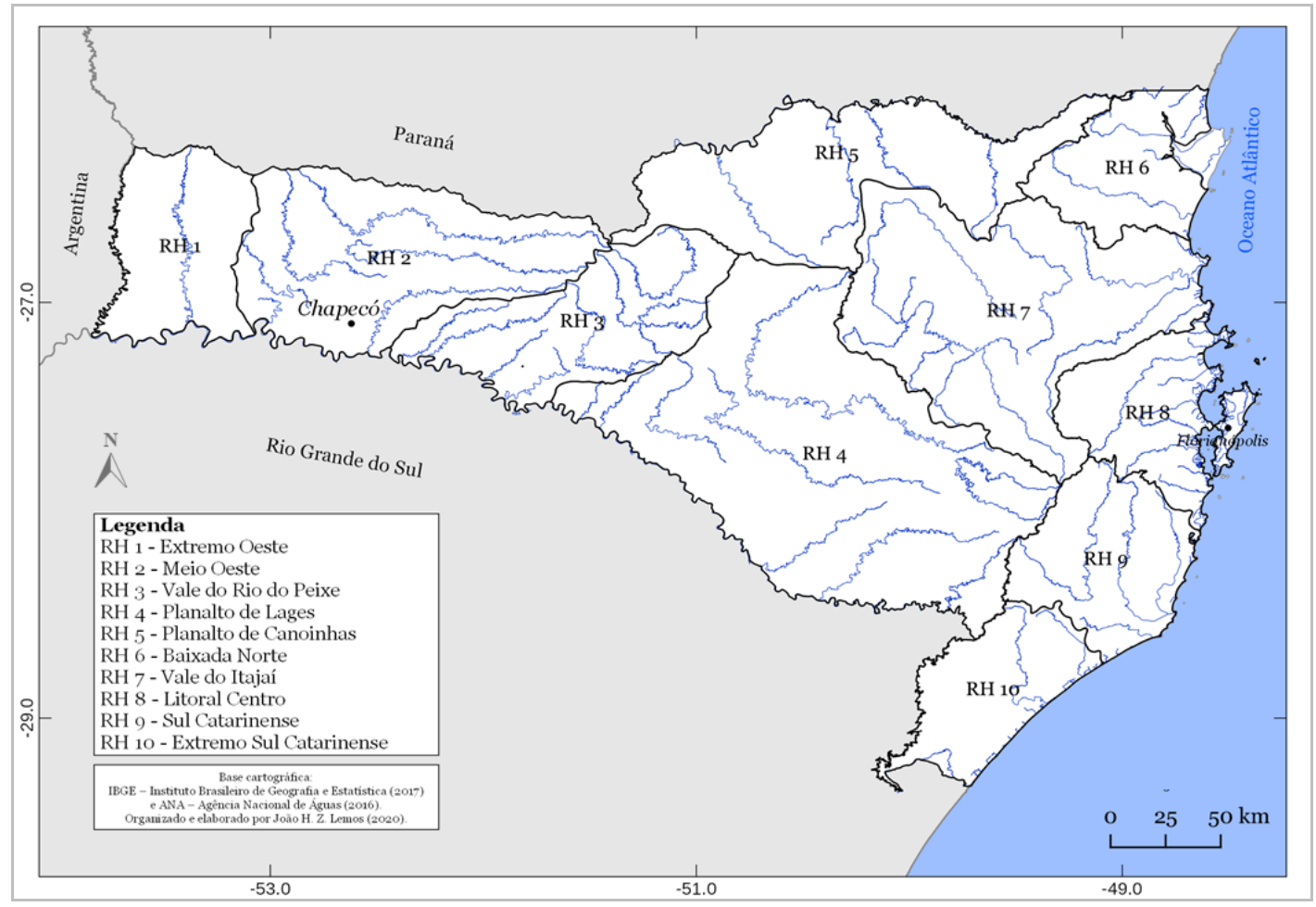

Fonte: ANA (2016); IBGE (2017). Elaboração: LEMOS (2020).

Chapecó é o município de maior referência na RH2 - Meio Oeste. Polo industrial regional, considerado cidade média em função das suas articulações nas dinâmicas econômicas nacionais e internacionais.

As BHUsC serão delimitadas aqui conforme proposto por Binda (2015), sendo definidas, portanto, como: lajeado São José; lajeado Rodeio Bonito, lajeado Lambedor, 
lajeado Passo dos Índios, lajeado Monte Alegre, lajeado da Divisa, lajeado Taquarassuzinho e lajeado Ferreira conforme Figura 3.

Figura 3 - Localização das bacias hidrográficas urbanas
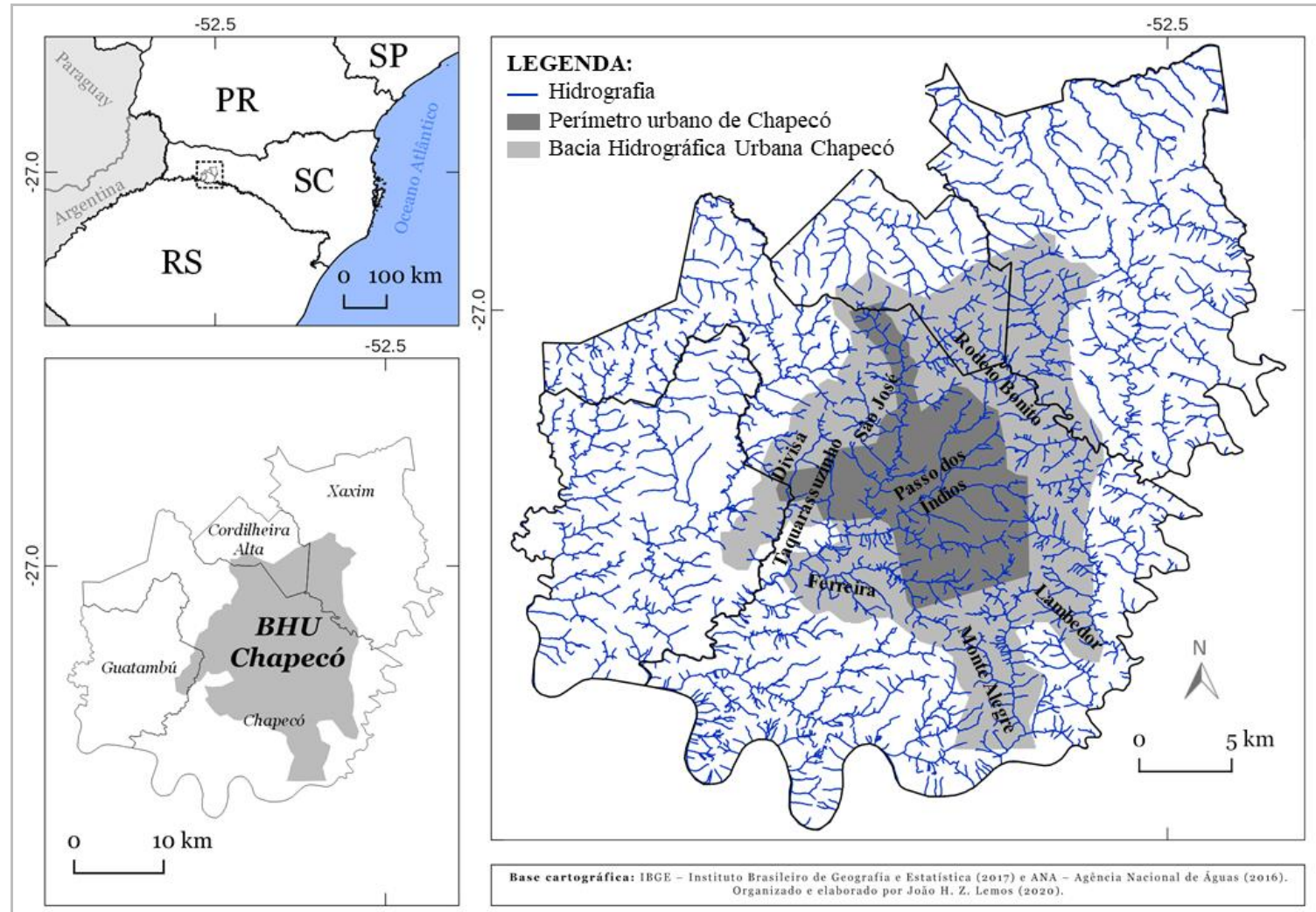

Fonte: ANA (2016); IBGE (2017). Elaboração e edição: LEMOS (2020); SEGNOR (2020).

As oito BHUsC concentram-se, independentemente de sua extensão territorial, no eixo noroeste de Chapecó, área de expansão prioritária desde à década de 1970. Note que a junção delas ultrapassa os limites territoriais do município, envolvendo o território de Guatambu, Cordilheira Alta e Xaxim.

Duas delas merecem destaque nesta análise, a bacia hidrográfica urbana do lajeado Passo dos Índios e do lajeado São José. A bacia do lajeado Passo dos Índios foi a primeira a ser ocupada, ainda em 1920 com o primeiro núcleo de colonização europeu proveniente do Rio Grande do Sul, que chamou o local, na época, de Vila Passo dos Índios (BELLANI, 1990) em alusão a hidrografia. Não apenas do ponto de vista histórico, esta bacia é importante por se constituir como a principal de Chapecó, visto que representa aproximadamente $43 \%$ do perímetro urbano atual (BINDA, 2015), já consolidado por se localizar majoritariamente na área central e bairros imediatos.

Já a bacia do lajeado São José, é aquela responsável pelo abastecimento de água da cidade e a segunda com maior influência na área urbana, abrangendo $26 \%$ 
de sua totalidade urbanizada (BINDA, 2015). A utilização das águas dessa bacia para abastecimento iniciou na década de 1970, mesmo período em que sua ocupação começa a ser incentivada pela municipalidade através do Plano Diretor de 1974, que visava à expansão da área em função do eixo industrial que ali iniciava sua instalação (FACCO, 2011). A partir disso, a urbanização e industrialização se fortificam na área do manancial e loteamentos e bairros surgem na região dada a necessidade de moradias para os funcionários das indústrias próximas (FACCO et al, 2014).

Conforme Rech (2008), essa ocupação na área da bacia do lajeado São José, inicia um processo que rompe a dinâmica de expansão em círculos a partir do centro presente até então no município. Dessa forma, a urbanização que se iniciou na bacia do lajeado Passo dos Índios, se expandiu principalmente em direção a do lajeado São José e posteriormente à do lajeado Taquarussuzinho, confirmando o crescimento urbano enfaticamente nos eixos norte e oeste (BINDA, 2015, FACCO et al 2014).

Atualmente, a negligência de Chapecó com seus corpos hídricos é relembrada a cada evento de inundação ou alagamento que ocorre na cidade. Essas problemáticas escancaram um planejamento urbano impensado desde sua gênese que ainda é reproduzido, mediado pelas relações de poder e lucro entre alguns agentes presentes no cotidiano da cidade.

Apesar de explícita a diferença no que concerne os aspectos sociais, espaciais e ambientais no município, principalmente em relação às áreas mais centralizadas e as bordas da cidade, as alterações na hidrologia urbana e suas consequências (alagamentos e inundações) são mais visíveis, ou pelo menos mais consideradas, em bairros como o Centro e seus arredores que correspondem à bacia hidrográfica do lajeado Passo dos Índios. Isso pode ser justificado pela massiva impermeabilização do solo pela urbanização e as canalizações nos córregos (Figura 4) que atravessam essa região, em contraste com as paisagens ainda menos alteradas e urbanizadas das demais bacias. 
Figura 4 - Canalizações no lajeado Passo dos Índios

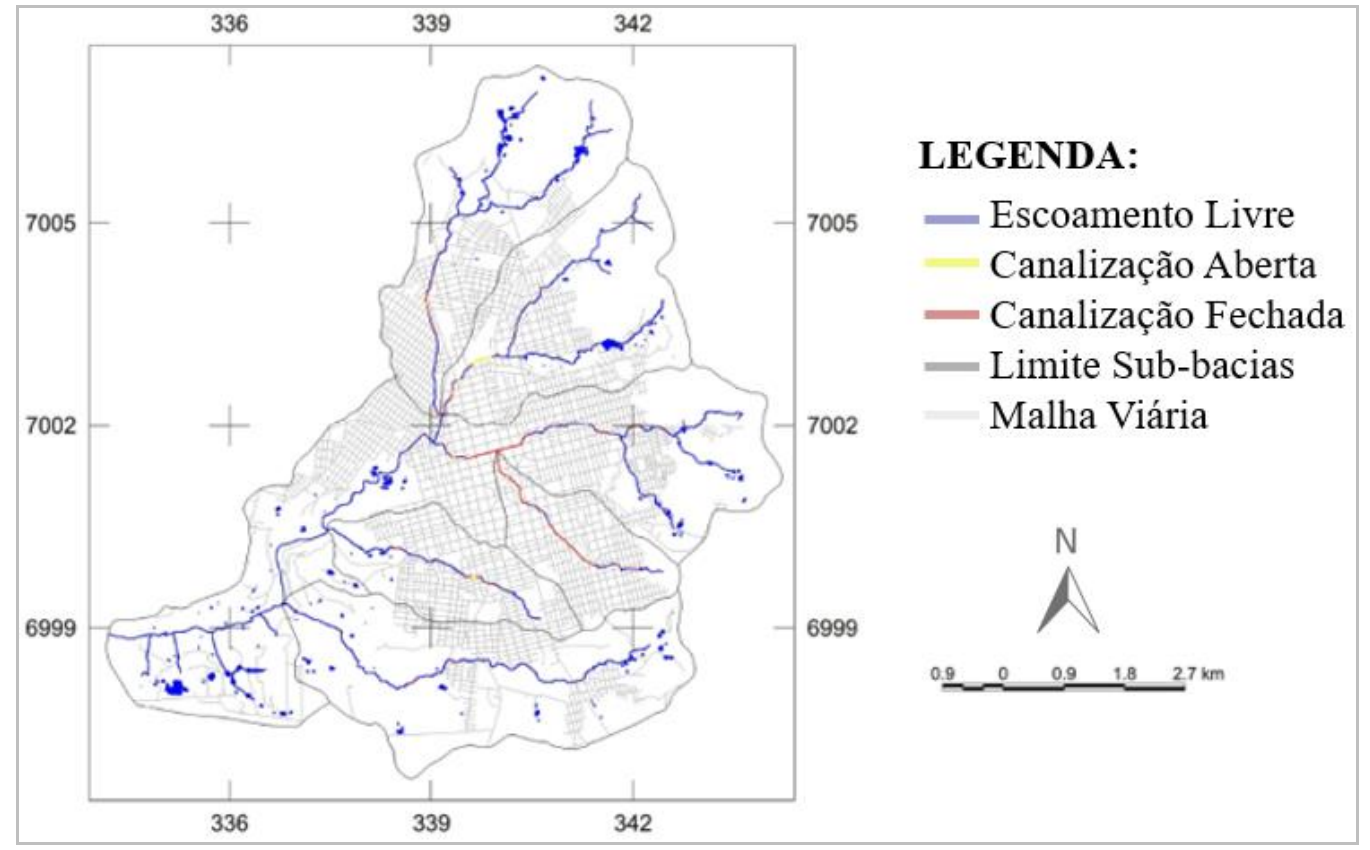

Fonte: BINDA E FRITZEN (2013). Edição: SEGNOR (2019).

As canalizações na bacia hidrográfica urbana do lajeado Passo dos Índios estão concentradas justamente na área central de Chapecó, onde os cursos d'água foram considerados "empecilhos" ao crescimento urbano. Atente-se para o fato de que conforme estes cursos ingressam ou egressam da área urbana eles passam a ter seu escoamento livre.

Embora, como citam Binda et al (2012), os casos de inundações e alagamentos são recorrentes desde a década de 1980, todavia, até esse período eles eram homogeneizados na malha urbana. A partir da década de 1990, sobretudo de 2000, esses problemas tornaram-se mais frequentes, espalhando-se por outros bairros (Figura 5), que começaram a apresentar pontos críticos em decorrência dessas situações. 
Figura 5 - Espacialização dos casos de inundações e alagamentos no período de 1980 a 2010 nos bairros de Chapecó
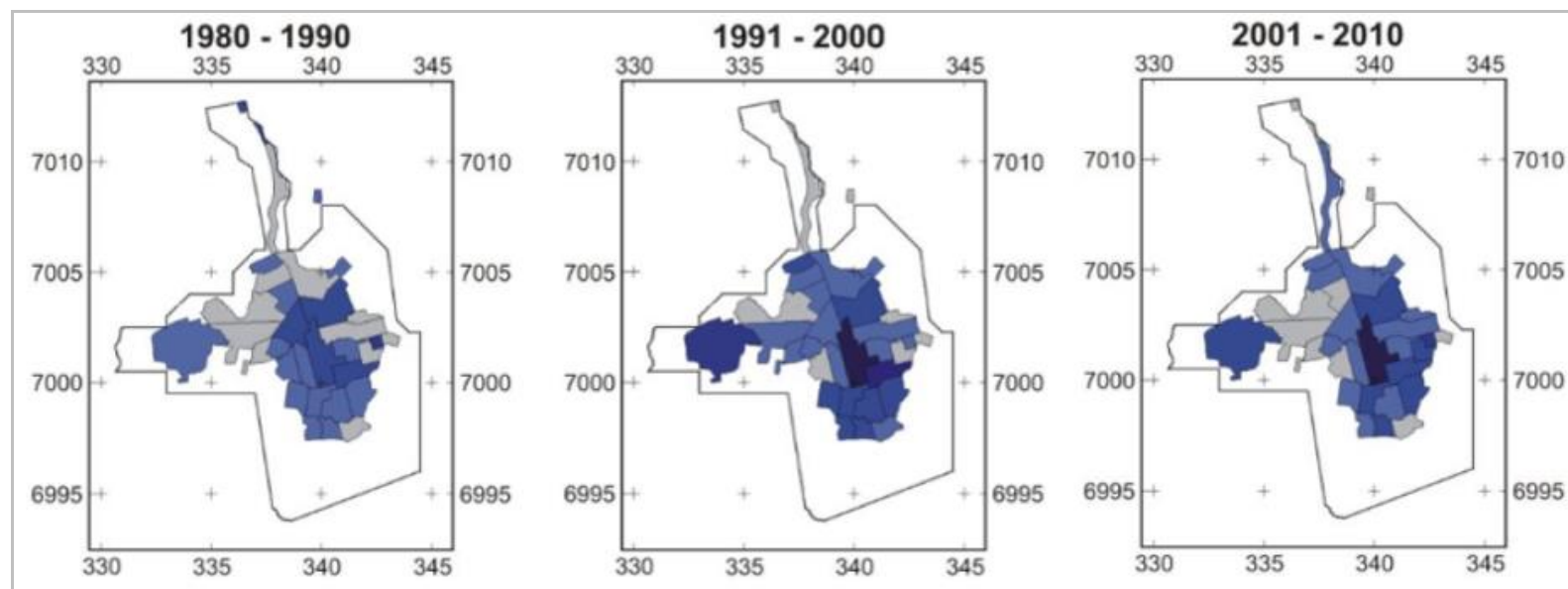

LEGENDA:
$1-3$
$10-12$
$4-6$
$7-9$
$13-15$
Sem dados
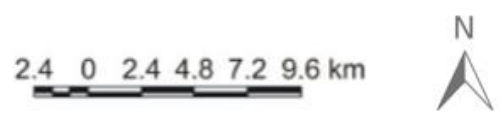

Fonte: BINDA et al (2012). Edição: SEGNOR (2020).

Observe como a incidência dos casos aumentou na área central ao mesmo tempo em que se alastrou por outros trechos da área urbana.

Essa incidência ainda no decênio de 1980 coincide com o momento em que a população urbana se torna majoritária em Chapecó. Porém, não apenas a questão demográfica foi responsável pelo aumento das inundações e alagamentos neste período, a infraestrutura urbana incompatível com a realidade, sobretudo a deficiência no sistema de drenagem de águas pluviais já subdimensionado para o volume de água atrelado ao aumento de pluviosidade devido ao fenômeno oceânicoatmosférico El Niño Oscilação Sul (ENOS) colaboraram para ocorrência de tais eventos, como cita Binda (2015).

Como solução, o poder público municipal canalizou os trechos crônicos dos lajeados Passo dos Índios, Bela Vista, Santo Antônio (DIÁRIO DA MANHÃ, 1984a in BINDA, 2015), e Passo dos Fortes (DIÁRIO DA MANHÃ, 1987a in BINDA, 2015), todos incorporados a bacia hidrográfica urbana do lajeado Passo dos Índios. Momentaneamente, essas intervenções (canalização e retificação) associadas a diminuição dos índices pluviométricos resolveram os episódios de inundações e 
alagamentos, contudo, a reincidência, agora mais abrangente e frequente, destes mesmos eventos na década seguinte colocaram em xeque esta solução.

As décadas que se sucederam, continuaram sendo marcadas por intervenções a partir de medidas estruturais nos cursos d'água da área urbana, que resolviam apenas temporariamente os problemas. Somente em 2005, ocorre uma tentativa de instituir uma medida não estrutural para controle das inundações em Chapecó, o chamado Projeto Sangas. Porém, o projeto que tinha por finalidade identificar e analisar a qualidade das águas dos rios de Chapecó, abordando a questão do uso do solo e seus reflexos ambientais (MPSC, 2005) não passou de uma limpeza e dragagem convencional, segundo Binda (2015).

\subsection{0 comitê da bacia hidrográfica do rio Chapecó e Rio Irani}

As bacias hidrográficas da região do rio Uruguai possuem 16 Comitês de Gerenciamento de Bacias constituídos em Santa Catarina - rios Canoas, Peixe, Jacutinga, Chapecó-Irani, Antas e Bacias contíguas - e no Rio Grande do Sul - rios Apuaê-Inhandava, Várzea, Passo Fundo, Turvo-Santa Rosa-Santo Cristo, ljuí, Piratinim, Butuí-Camaquã, Ibicuí, Quaraí, Santa Maria e Negro (SAMAE, 2014).

Embora o município de Chapecó esteja inserido entre as bacias do rio Irani e do rio Chapecó, do ponto de vista institucional e de gerenciamento de recursos hídricos suas bacias urbanas e rurais, que drenam diretamente para o rio Uruguai, são incorporadas a bacia do rio Chapecó (SANTA CATARINA, 2013). Dessa forma, as bacias hidrográficas chapecoenses, assim como os demais corpos hídricos da região, são reguladas pelo Comitê Chapecó/Irani, criado através do decreto $n^{\circ} 3.498$, de 8 de setembro de 2010 .

O Comitê de Gerenciamento das Bacias Hidrográficas dos Rios Chapecó e Irani e Bacias Hidrográficas Contíguas, órgão de caráter consultivo e deliberativo regional, abrange 60 munícipios da região oeste do estado, numa área de $11.122 \mathrm{~km}^{2}$ (SIRHESC, 2019) e população superior à 660mil habitantes (IBGE, 2019b). Em geral, a maioria dos municípios que fazem parte desta RH2 (Região Hídrica 2) são pequenos, com menos 
de 10mil habitantes, e tiveram seu processo de ocupação a partir do século XX. Suas paisagens foram e continuam sendo modificadas por atividade econômica extrativista, agropecuária, industrial (VALENTINI et al, 2019) e, mais recentemente, hidrelétrica e turística.

Na RH2 (Região Hidrográfica 2) - Meio Oeste, a contaminação dos cursos hídricos e tem como principais fontes de contaminação o setor agropecuário (dejetos animais e agrotóxicos), industrial e os esgotos gerados nas cidades (SANTA CATARINA, 2009). Essas condições também são observadas nas bacias hidrográficas urbanas de Chapecó, principalmente na do lajeado Passo dos Índios e lajeado São José. sobre essas condições Baldissera (2013) expõem que:

\footnotetext{
O impacto ambiental da ação antrópica de contaminação das bacias hidrográficas afetou águas superficiais e subterrâneas, se dando tanto por vias diretas - poluição por despejo de efluentes doméstico, agroindustrial e industrial - quanto por vias indiretas - remoção de florestas ripárias, uso e ocupação inadequados do solo ao longo dos cursos d'água, ou poluição difusa, gerada em grande parte pelos deflúvios contaminados provenientes das áreas urbanas e áreas de agricultura, significativas causas e fontes de degradação, além das enchentes que permanecem a cada chuva mais intensa (BALDISSERA, 2013, p.150).
}

Em se tratando da bacia do Passo dos Índios, totalmente inserida na área urbana, houve tentativas, por meio de investimentos públicos em saneamento, de amenizar os impactos ambientais. Entretanto, com redes de esgoto restritas à área central, os cursos de água ainda são utilizados como canais de esgoto e suas margens como depósitos de resíduos. Já em relação a bacia do lajeado São José cujas características ainda são predominantemente rurais - apenas $15 \%$ de sua área encontra-se urbanizada - até a década de 1980, os problemas sanitários estavam relacionados às atividades agropecuária. Uma vez que essas condições comprometiam o abastecimento de água para a cidade, intervenções da EPAGRI e da Secretaria da Agricultura, aliada a desativação de granjas de suínos, foram efetuadas. Contudo essas condições favoreceram o processo de urbanização da bacia, mesmo com legislações proibitivas, o que fez com que os problemas apenas mudassem de foco: a contaminação orgânica agora tornava-se contaminação por resíduos sólidos, como lixo, assoreamento e esgotos sanitários sem tratamento (BALDISSERA, 2013). 
São essas condições insalubres em que se encontram os recursos hídricos que se faz necessária ação de diversos agentes, por meio de instrumentos de proteção e planejamento sustentável, tais como as desempenhadas pelo Comitê Chapecó/Irani. Embora o Comitê ainda se constitua como um órgão recente, sua importância na gestão das bacias hidrográficas é primordial, visto que entre seus objetivos está o combate e a prevenção das causas e efeitos adversos da poluição, das inundações, das estiagens, da erosão do solo e do assoreamento dos corpos de água nas áreas urbanas e rurais (SIRHESC, 2019). Proteger os recursos hídricos contra ações que possam comprometer o uso atual e futuro, é pauta urgente nas cidades, que sempre será permeada por conflitos urbano-ambientais.

\section{CONSIDERAÇÕES FINAIS}

A bacia hidrográfica é a esfera de interação das águas com o meio físico, o meio biótico e o meio social, econômico e cultural (YASSUDA, 1993). Assim, os problemas socioambientais que as envolvem, necessitam de uma ação integrada que englobe diferentes esferas político-administrativas e participação popular, já que sua abrangência pode ultrapassar os limites territoriais de países, estados ou municípios (CUNHA e COELHO, 2003).

É necessária, nessa medida, uma mudança que altere o padrão de planejamento da cidade de modo a envolver integralmente o planejamento urbano, o uso do solo, o esgotamento sanitário, os resíduos sólidos e a drenagem urbana, considerando inclusive o manancial e as inundações ribeirinhas naturais, uma vez que esses elementos possuem forte interferência entre si e necessitam de soluções integradas (TUCCI, 2003; CRUZ e TUCCI, 2008).

A recorrência de inundações e alagamentos em Chapecó não é algo isolado uma vez que reflete a mesma problemática que ocorre na maioria das cidades brasileiras. Não raro, são adotadas medidas corretivas pontuais que resolvem os problemas temporariamente ou simplesmente os deslocam de lugar. Gerir o espaço urbano também significa gerenciar a drenagem urbana, contudo, o instrumento 
utilizado para esse planejamento, como o Plano Diretor Urbano (PDU), está geralmente focado em aspectos arquitetônicos e urbanísticos em detrimento ao sistema de drenagem (CRUZ et al 2007).

Nesse sentido, a instituição de um Plano Diretor de Drenagem Urbana (PDDrU) ou ainda a utilização de medidas corretivas não convencionais (BMP ou LID) que prezem por sistemas de drenagem sustentáveis para Chapecó, representam possibilidades de resgatar e revalorizar os cursos d'água em sua área urbana. Importante citar que o PDDrU contempla estratégias tanto para áreas não ocupadas (a partir de medidas não estruturais como legislação e regulamentação sobre o aumento da vazão resultante da urbanização e da ocupação dos espaços de risco de áreas ribeirinhas além de gestão dos serviços urbanos relacionados com as águas pluviais a fim de conter impactos futuros), quanto para áreas que já estão ocupadas e com o desenvolvimento de estudos específicos nas microbacias urbanas com o propósito de instituir medidas que controlem os impactos já existentes sem que eles sejam transferidos à jusante (TUCCl, 2003).

Em suma, embora os Planos Diretores de Drenagem Urbana se constituam como um importante recurso, apenas sua implantação nas cidades não assegura a resolução dos problemas na drenagem. A solução, em sua forma integral ou mitigatória, depende de uma conjunção de esforços e ações de diversos atores representantes de vários setores urbanos, sob coordenação do poder público municipal, dos agentes produtores desse espaço e, sobretudo, da participação cidadã da população que reside sobre essas bacias hidrográficas, com iniciativas que preconizem o reconhecimento dos bens hídricos, a consciência e a educação ambiental para sua preservação.

\section{AGRADECIMENTOS}

Os estudos que embasaram a produção do presente artigo tiveram apoio científico financeiro da Fundação de Amparo à Pesquisa e Inovação de Santa Catarina (FAPESC). 


\section{REFERÊNCIAS}

ALBA, R. S., et al. Dinâmica populacional no oeste catarinense: indicadores de crescimento populacional dos maiores municípios. In: BRANDT, M. e NASCIMENTO, E. (Orgs.). Oeste de Santa Catarina: Território, Ambiente e Paisagem. São Carlos: Pedro \& João Editores, 2015. p. 41-69.

ANDRADE, T. A.; LODDER, C. A. Sistema urbano e cidades médias no Brasil. Rio de Janeiro: IPEA/INPES, 1979 (Coleção Relatórios de Pesquisa, n. 43).

BALDISSERA, A. D. A cidade e as águas: Chapecó e a microbacia do lajeado São José. 2013. 226p. Dissertação (Mestrado em Urbanismo, História e Arquitetura da Cidade) - Universidade Federal de Santa Catarina, Florianópolis.

BELLANI, Eli Maria. Santos Marinho e Passos Maia: a política no Velho Chapecó (1917-1931). Chapecó: Litoprint. 1990.

BINDA, A. L. Os rios urbanos de Chapecó: do esquecimento sob as lajes de concreto às recordações nos dias de chuva. In: BRANDT, M. e NASCIMENTO, E. (Orgs.). Oeste de Santa Catarina: Território, Ambiente e Paisagem. São Carlos: Pedro \& João Editores, 2015. p. 155-193.

BINDA, A. L.; BUFFON, E. A. M.; FRITZEN, M. Análise espaço-temporal dos casos de inundações e de alagamentos registrados na cidade de Chapecó-SC (1980-2010). Ra E'Ga, v. 26, p. 35-50, 2012.

BINDA, A. L.; FRITZEN, M. Uso do solo urbano e alterações na rede de drenagem da bacia hidrográfica do Lajeado Passo dos Índios, Chapecó-SC. Geografia Ensino \& Pesquisa, v.17, n. 2, p.243-259, maio/ago. 2013.

BOTELHO, R. G. M. Bacias Hidrográficas Urbanas. In: GUERRA, A. J. T. (Org.). Geomorfologia Urbana. Rio de Janeiro: Bertrand Brasil, 2011. p.71-115.

BRASIL. Programa Drenagem Urbana Sustentável. Manual para apresentação de propostas. Brasília, DF: Ministério das Cidades. 2007. 33 p.

CANCELIER, J. W. et al. A expansão urbana de Chapecó -SC e os papéis dos agentes sociais territoriais. Reget, v. 19, n.2, p. 717-734, mai/ago 2015.

CANHOLI, A. P. Drenagem urbana e controle de enchentes. 2. ed. São Paulo: Oficina de Textos, 2014.

CATELAN, M. J. Heterarquia urbana: interações espaciais interescalares e cidades médias. São Paulo: Cultura Acadêmica. 2013.

CHAPECÓ. Chapecó em dados - 2011 Disponível em: http://www.chapeco.sc.gov.br/chapeco/chapeco-dados.html. Acesso em: 20 set.2020.

CRUZ, M. A. S.; SOUZA, C. F.; TUCCl, C. E. M. Controle da Drenagem Urbana no Brasil: Avanços e mecanismos para sua sustentabilidade. In: SIMPÓSIO DE RECURSOS HÍDRICOS, 17, 2007, São Paulo. Anais.... Porto Alegre: ABRH, 2007. 
CRUZ, M. A. S. e TUCCI, C. E. M. Avaliação dos cenários de planejamento na Drenagem Urbana. RBRH - Revista Brasileira de Recursos Hídricos, v.13 n.3, p.59-71, jul/set 2008.

CUNHA, S. B. da. Canais fluviais e a questão ambiental. In: CUNHA, S. B.; GUERRA, A. J. T. (Orgs.). A questão ambiental: diferentes abordagens. Rio de Janeiro: Bertrand Brasil, 2003. p. 219-237.

CUNHA, L. H. e COELHO, M. C. N. Política e Gestão Ambiental. In: CUNHA, S. B.; e GUERRA, A. J. T. (Orgs.). A questão ambiental: diferentes abordagens. Rio de Janeiro: Bertrand Brasil, 2003. p.4380.

DEBONA, D. Governo investe R\$ 3 milhões em comitês de bacias hidrográficas. NSC Total. Florianópolis. 2019. Disponível em: https://www.nsctotal.com.br/noticias/governo-investe-r-3milhoes-em-comites-de-bacias-hidrograficas. Acesso em: 14 nov.2019.

FACCO, J. Os conflitos ambientais no processo de urbanização na bacia hidrográfica de abastecimento de água de Chapecó-SC. 2011. 231p. Dissertação (Mestrado em Ciências Ambientais) - Universidade Comunitária Regional de Chapecó, Chapecó.

FACCO, J.; FUJITA, C.; BERTO, J. L. Agroindustrialização e urbanização de Chapecó-SC (1950-2010): uma visão sobre os impactos e conflitos urbanos e ambientais. Rev. Des. Regional, v. 19, n. 1, p. 187-215, 2014.

FERREIRA, S. C. Rede urbana, cidade de porte médio e cidade média: estudos sobre Guarapuava no estado do Paraná. 2010. 298p. Tese (Doutorado em Geografia) - Universidade Estadual Paulista, São Paulo.

FURTADO, C. Formação econômica do Brasil. 26. ed. São Paulo: Nacional 1997.

INSTITUTO BRASILEIRO DE GEOGRAFIA E ESTATÍ́STICA - IBGE. Pesquisa Nacional de Saneamento Básico. Rio de Janeiro: IBGE, 2000. Disponível em: https://sidra.ibge.gov.br/tabela/2227. Acesso em: 12 out. 2019.

INSTITUTO BRASILEIRO DE GEOGRAFIA E ESTATÍSTICA - IBGE. Regiões de Influência de Cidades. Rio de Janeiro: IBGE, 2008.2 Disponível em: https://biblioteca.ibge.gov.br/visualizacao/livros/liv40677.pdf. Acesso em: 12 out.2019.

INSTITUTO BRASILEIRO DE GEOGRAFIA E ESTATÍSTICA - IBGE. Área da unidade territorial. 2019a. Disponível em: https://cidades.ibge.gov.br/brasil/sc/chapeco/panorama. Acesso em: 20 set.2020.

INSTITUTO BRASILEIRO DE GEOGRAFIA E ESTATÍSTICA - IBGE. IBGE Cidades. 2019b. Disponível em: https://cidades.ibge.gov.br/. Acesso em: 07 nov.2019.

INSTITUTO BRASILEIRO DE GEOGRAFIA E ESTATÍSTICA - IBGE. Censo demográfico 2010. Rio de Janeiro: IBGE, 2011.

IPH. Manual de Drenagem Urbana. Porto Alegre, RS: Departamento de Esgotos Pluviais, 2005. $167 p$.

LOHN, R. L. Entre a ditadura e a democracia: transformações urbanas e democratização nas páginas dos jornais - um tempo presente brasileiro (o caso de Florianópolis, SC, 1964-1990). In: 
XXVI SIMPÓSIO NACIONAL DE HISTÓRIA, 2011, São Paulo. Anais... São Paulo: ANPUH, 2011. p.117.

MARICATO, E. Brasil, cidades: alternativas para a crise urbana. Petrópolis: Vozes, 2001.

MARICATO, E. Metrópole, legislação e desigualdade. Estudos Avançados, v. 17, n. 48, p. 151-166. 2003.

NASCIMENTO, E. Chapecó: evolução urbana e desigualdades socioespaciais. In: BRANDT, M. e NASCIMENTO, E. (Orgs.). Oeste de Santa Catarina: Território, Ambiente e Paisagem. São Carlos: Pedro \& João Editores, 2015. p. 97-153.

PELUSO JÚNIOR, V. A. O relevo do território catarinense. Geosul, n. 2, p. 7-69, 1986.

RECH, D. Leis e planos urbanos na produção da cidade: o caso de Chapecó, SC. 2008. 154p. Dissertação (Mestrado em Urbanismo, História e Arquitetura da Cidade) - Universidade Federal de Santa Catarina, Florianópolis.

RIGHETTO, A.M. Hidrologia e recursos hídricos. São Carlos: EESC/USP, 1998.

ROLNIK, R. Regulação Urbanística no Brasil: conquistas e desafios de um modelo em construção. In: SEMINÁRIO INTERNACIONAL: GESTÃO DA TERRA URBANA E HABITAÇÃO DE INTERESSE SOCIAL, 2000, São Paulo. Anais... São Paulo: PUCCAMP, 2000. p. 1-19.

SAMAE. Serviço Autônomo Municipal de Água e Esgoto. Campos Novos é sede de encontro de comitês de bacias hidrográficas. 2014. Disponível em: https://www.camposnovos.sc.gov.br/noticias/index/ver/codMapaltem/6494/codNoticia/102952. Acesso em 14 nov.2019.

SANTA CATARINA. Plano estratégico de gestão integrada da Bacia Hidrográfica do Rio Chapecó. Florianópolis, SC: SDS/MPB engenharia, 2009.

SANTA CATARINA. MPSC Iança Projeto Sangas para avaliar situação dos rios de Chapecó. Ministério Público. 2005. Disponível em: https://mpsc.mp.br/noticias/mpsc-lanca-projeto-sangaspara--avaliar-situacao-dos-rios-de-chapeco. Acesso em: 12 out.2019.

SANTA CATARINA. Plano de manejo da Floresta Nacional de Chapecó. Florianópolis, SC: ICMBio. 2013. 193p.

SANTOS, M. A urbanização brasileira. São Paulo: Hucitec, 1993.

SANTOS, M; SILVEIRA, M L. O Brasil: Território e sociedade no início do século XXI. 9. ed. Rio de Janeiro: Record, 2006.

SIRHESC. Sistema de Informação de Recursos Hídricos do Estado de Santa Catarina. Comitê Chapecó/Irani. Disponível em: http://www.aguas.sc.gov.br/o-comite-rio-chapeco-irani/inicial-riochapeco-irani. Acesso em 14 nov.2019.

SOUZA, M. L. de. A B C do desenvolvimento urbano. Rio de Janeiro: Bertrand Brasil, 2003. 
SPOSITO, M. E. B. Novas redes urbanas: cidades médias e pequenas no processo de globalização. Geografia, v. 35, n. 1, p. 51-62, jan/abr 2010.

STAMM, C. et al. A população urbana e a difusão das cidades de porte médio no Brasil. Interações, v. 14, n. 2, p. 251-265, jul./dez. 2013.

TUCCl, C. E. M. Inundações e drenagem urbana. In: TUCCl, C. E. M. \& BERTONI, J. C. (Orgs.). Inundações urbanas na América do Sul. Porto Alegre: Associação Brasileira de Recursos Hídricos, 2003. p. $45-150$.

TUCCI, C. E. M. Gestão de Águas Pluviais Urbanas. Brasília, DF: Ministério das Cidades/Global Water Partnership/World Bank/Unesco, 2005. 270p.

VALENTINI, D. R. O ordenamento territorial como agente de produção da forma urbana e do sistema de espaços livres no município de Chapecó-SC. 2015. (Apresentação de Trabalho/Congresso).

VALENTINI, D. R.; FACCO, J.; PASSOS, M. G. dos. Paisagem e desenvolvimento regional: um estudo a partir da região hidrográfica dos rios Chapecó e Irani (RH2). In: SILVESTRE, L. P. F. (Org.) As ciências humanas e sociais aplicadas e a competência no desenvolvimento humano. Ponta Grossa: Atena Editora, 2019. p.56-68.

VIEIRA, V.; CUNHA, S. b. Mudanças na rede de drenagem urbana em Teresópolis (Rio de Janeiro). In: GUERRA, A. J. T.; CUNHA, S. B. (Orgs.). Impactos Ambientais Urbanos no Brasil. Rio de Janeiro: Bertrand Brasil, 2001. p. 111-142.

YASSUDA, E. R. Gestão de recursos hídricos: fundamentos e aspectos institucionais. Rev. Adm. Púb., v.27, n.2, p.5-18, 1993.

ZANDONADI, J. C. Cidades médias e cidades de porte médio: distinção a partir de situações geográficas interurbanas e dinâmicas da centralidade intraurbana - Uma análise comparativa de Taboão da Serra (SP), São Carlos (SP) e Marília (SP). 2013. 273p.Tese (Doutorado em Geografia) - Universidade Estadual de Campinas, Campinas.

ZENI, V. L. F. Desenvolvimento de cenários visando a mitigação de impactos ambientais em rios urbanizados: o caso do rio Passo dos Índios - Chapecó - SC. 2007. 150p. Dissertação (Mestrado em Ciências Ambientais) - Universidade Comunitária Regional de Chapecó, Chapecó.

\footnotetext{
${ }^{1}$ Neste caso a expressão "cidades de porte médio" é empregada no sentido demográfico, cuja população urbana situava-se entre 100 mil a 500 mil habitantes.

${ }^{2} \mathrm{O}$ conceito de cidade dual foi desenvolvido por Castells (1995) e se refere à manifestação da estrutura urbana, social e economicamente polarizada.

${ }^{3}$ Para a autor, "a heterarquia urbana representa o que é a rede de fato quais são suas propriedades, como elas se articulam e quais seus atributos que são, dentre outros conteúdos, o espaço, as escalas geográficas, os agentes econômicos e o capital". (CATELAN, 2013, p. 38).
} 
${ }^{4}$ O Ministério das Cidades, criado em 2003, foi fundido no início de 2019 ao Ministério da Integração Regional e transformado em Ministério do Desenvolvimento Regional. Fonte: <https://g1.globo.com/jornalnacional/noticia/2018/12/03/governo-bolsonaro-anuncia-que-tera-22-ministros-7-ministerios-seraoextintos.ghtml> Acesso em out/2019.

${ }^{5}$ A população estimada para Chapecó em 2019 conforme IBGE é de 220.367 habitantes. Disponível em: $<$ https://cidades.ibge.gov.br/> Acesso em: out/2019.

${ }^{6}$ Conforme o último Censo Demográfico (IBGE, 2010) realizado, a população total de Chapecó correspondia a 183.530 habitantes, dos quais $91,6 \%$ (ou 168.159 hab) residiam na área urbana em comparação a 8,4\% (ou a 15.417hab) residentes na área rural. Disponível em: <https://cidades.ibge.gov.br/> Acesso em: out/2019. 